\title{
Th2 Dominance Might Induce Carcinogenesis in Patients with HCV-related Liver Cirrhosis
}

\author{
MICHIO KOGAME ${ }^{1}$, HIDENARI NAGAI ${ }^{1}$, MIE SHINOHARA ${ }^{1}$, \\ YOSHINORI IGARASHI ${ }^{1}$, YASUKIYO SUMINO ${ }^{1}$ and KOJI ISHII ${ }^{2}$ \\ ${ }^{1}$ Division of Gastroenterology and Hepatology, Department of Internal Medicine (Omori), \\ School of Medicine, Faculty of Medicine, Toho University, Tokyo, Japan; \\ ${ }^{2}$ Division of Gastroenterology and Hepatology, Tokyo Kamata Medical Center, \\ Japan Community Health Care Organization, Tokyo, Japan
}

\begin{abstract}
Background/Aim: It has been reported that type 2 helper T-cell (Th2) cytokines down-regulate antitumor immunity, while Th1 cytokines up-regulate it. We previously reported that hepatocarcinogenesis was associated with Th2 dominance in patients with hepatitis $C$ virus $(\mathrm{HCV})$-related liver cirrhosis (LC), but we did not determine whether Th2 dominance induced carcinogenesis or carcinogenesis led to Th2 dominance. The aim of the study was to clarify whether Th2 dominance induces carcinogenesis or vice versa in patients with HCV-related liver diseases. Patients and Methods: The study population was 82 adult Japanese patients who had chronic inflammation due to HCV infection diagnosed by pathological examination of liver biopsy specimens, including 21 patients with early hepatocellular carcinoma (eHCC) and HCV-related LC. All patients were admitted to our hospital between 2008 and 2014. eHCC was treated by radiofrequency ablation (RFA). The non-HCC patients were divided into four subgroups based on the fibrosis score of Desment (stage F1-4). Blood samples were collected just before starting RFA and after 4 weeks of RFA. Flow cytometry was used to assess the percentages of IFN $\gamma^{+}$

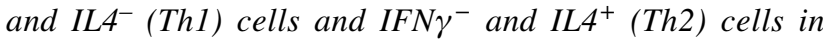
$C D 4^{+} T$-cells of peripheral blood before the start of each RFA session. Results: There were 21 patients with fibrosis stage 1, 21 with stage 2, 18 with stage 3, 22 with stage 4, and 21 patients with eHCC. Before RFA, Th1 cells were
\end{abstract}

Correspondence to: Hidenari Nagai, Division of Gastroenterology and Hepatology, Department of Internal Medicine (Omori), School of Medicine, Faculty of Medicine, Toho University, 6-11-1, Omorinishi, Ota-ku, Tokyo, 143-8541, Japan. Tel: +81 33762415, Fax:+81337638542, e-mail: hidenari@aol.com

Key Words: Hepatocellular carcinoma, carcinogenesis, radiofrequency ablation, host immunity, Th1 cells, Th2 cells. significantly more frequent in the F4 and eHCC groups than in the F1 group, although there was no significant difference between the HCC and F1 groups after RFA. Both before and after RFA, Th2 cells were significantly more frequent in the HCC group than in the F1 group. Conclusion: Th2 dominance was not altered by elimination of eHCC after RFA therapy. Therefore, Th2 dominance might induce carcinogenesis in patients with $\mathrm{HCV}$-related $\mathrm{LC}$ rather than carcinogenesis leading to Th2 dominance.

Hepatocellular carcinoma (HCC) is one of the most common types of cancers and causes 662,000 deaths worldwide annually (1). Chronic HCV infection of the liver is an important risk factor for the development of this type of cancer. Treatment of HCV infection has been revolutionized by introduction of direct-acting antiviral agents (DAAs) and the development of oral, interferon (IFN)-free DAA regimens that promise extremely high $(>90 \%)$ sustained virological response (SVR) rates (2). In patients with all stages of liver fibrosis, achieving SVR is reported to lead to marked reduction of all-cause mortality (3), progression of fibrosis (4), need for liver transplantation (5), extrahepatic complications (6), and hepatocarcinogenesis. However, recent studies have shown that the cumulative incidence of HCC at 5 and 10 years after SVR ranges from $2.3 \%$ to $3.1 \%$ and from $8.8 \%$ to $11.1 \%$, respectively (7). Most HCC develops in patients with a natural history of ongoing inflammation and severe fibrosis or cirrhosis, and liver fibrosis is reported to be the main independent risk factor for HCC (8). These clinical observations suggest that chronic inflammation due to $\mathrm{HCV}$ infection simultaneously induces hepatic fibrosis and carcinogenesis (fibro-carcinogenesis) $(9,10)$. It has been reported that the recurrence rate is lower and 5-year survival rate is higher for patients who have small tumors with prominent T-cell infiltration than those who have larger tumors without such infiltration, and that most tumor-infiltrating 
lymphocytes are immunohistochemistry identified as T-cells with predominance of $\mathrm{CD}^{+}$cells over $\mathrm{CD} 4^{+}$cells (11). It has also been reported that lymphocytic infiltration of the tumor and a high $\mathrm{CD}^{+} / \mathrm{CD}^{+}$cell ratio are associated with a lower risk of recurrence following liver transplantation (12). Therefore, the immunological background of patients with HCC seems to be important. Immature dendritic cells (DCs) in the liver exhibit low expression of major histocompatibility complex class II and co-stimulatory molecules (CD80 and CD86), lack CD1a, and produce suppressive cytokines such as interleukin-10 (IL10) (13). Mature DCs release a variety of cytokines (IL12, TNF $\alpha$, IL18, and IFN $\alpha$ ) that act on natural killer T-cells. In addition, mature DCs prime naive T-cells (Th0) and induce inflammatory $\mathrm{CD}^{+}$T-helper type 1 (Th1) cells and $\mathrm{CD}^{+}$cytotoxic T-cells. A high serum level of IL6 was found to be an independent risk factor for HCC in female patients with chronic hepatitis $\mathrm{C}$, but not in males (14). High IL10 expression in HCC tissues and elevated serum IL10 levels are also correlated with tumor progression (15). Furthermore, it has been reported that Th2 cytokines downregulate antitumor immunity (16), while Th1 cytokines upregulate it (17-20). We previously examined changes of peripheral blood $\mathrm{CD}^{+}{ }^{+} \mathrm{T}$-cells related to carcinogenesis in patients with HCV-related chronic hepatitis and liver cirrhosis (LC). We found that carcinogenesis was associated with Th2 dominance in patients with HCV-related LC (21). However, we did not determine whether $\mathrm{Th} 2$ dominance induced carcinogenesis or carcinogenesis led to Th2 dominance. Therefore, in order to clarify the relation between Th2 dominance and carcinogenesis in HCV-related liver diseases, we evaluated the changes of host immunity in patients with early HCC receiving radiofrequency ablation (RFA) therapy.

\section{Patients and Methods}

Patients. The study population was 103 adults Japanese patients who had chronic hepatitis due to HCV infection diagnosed by pathological examination of liver biopsy specimens, including 21 patients who had HCV-related LC with early HCC. All early HCCs were less than $30 \mathrm{~mm}$ in diameter and all were solitary tumors (mean diameter $=16.5 \pm 4 \mathrm{~mm}$, range $=10.8-20.0 \mathrm{~mm}$ ). These cancers were treated by RFA therapy. We previously reported that the blood levels of Th1 and Th2 cells significantly increase with age in healthy volunteers. However, this change is not seen in patients with HCV-related chronic hepatitis (22), so we eliminated the influence of age by enrolling patients more than 55 years old. All patients were admitted to our hospital between 1997 and 2014. Those without $\mathrm{HCC}$ were divided into four subgroups based on the fibrosis score of Desment (stage 1-4). Blood samples were collected in the early morning before the start of IFN therapy. In the patients with early HCC, blood samples were collected in the early morning before starting RFA therapy and after 4 weeks of RFA therapy.

Serum parameters and HCV-RNA. The platelet count, white blood cell (WBC) count, and serum levels of aspartate aminotransferase (AST) and alanine aminotransferase (ALT) were measured by standard procedures, while the HCV-RNA level was quantified with the Amplicor Ver 2.0 test or TaqMan Ver 2.0 test (Roche Molecular Diagnostics, Pleasanton, CA, USA).

Analysis of CD4-positive T-cell subsets. CD4-positive T-cell subsets in peripheral blood were analyzed after non-specific stimulation with phorbol 12-myristate 13-acetate (PMA), ionomycin, or brefeldin A (Sigma Chemical Co., St. Louis, MO, USA), according to the modified method of Jung et al. $(23,24)$.

Flow cytometry was used to detect cytoplasmic expression of IFN- $\gamma$ and IL4 by peripheral blood CD4-positive T-cells after culture and staining (23). The percentage of cytokine-producing cells in the $\mathrm{CD}^{+} \mathrm{T}$-cell population was determined separately for IFN $\gamma^{+} / \mathrm{IL} 4^{-}$(Th1) cells and IFN $\gamma^{-} / \mathrm{IL}^{+}$(Th2) cells (Figure 1). Regulatory T-cells (Treg cells) were identified as CD25high/ CD127low cells (Figure 2).

Evaluation of the response to RFA. Computed tomography was performed before starting RFA and after 4 weeks of RFA, and the tumor response was assessed according to the modified Response Evaluation Criteria in Solid Tumors $(25,26)$. In all patients with early HCC, disappearance of the tumor was confirmed.

Statistical analysis. Statistical analysis was performed by using the Statistical Package for the Social Sciences (SPSS version 11.0; SPSS, Chicago, IL, USA) and Ekuseru-Toukei 2010 (Social Survey Research Information Co., Ltd., Japan). Results are expressed as the mean \pm standard deviation (SD). Wilcoxon's signed-rank sum test was used to compare patient's characteristics within each group, while Dunnett's test was employed for comparisons between the control group and other groups. Normally distributed variables were compared between two groups with the Student's $t$-test, while other variables were compared by the Mann-Whitney $U$-test. A probability of less than 0.05 was considered to indicate statistical significance.

This study was approved by Ethical Review Board of Toho University Medical Center, Omori Hospital (number 23-170).

\section{Results}

Clinical profile of patients. The age and sex of patients grouped by staging are given in Table I. Among the 21 patients with early HCC, 17 patients were in Child-Pugh class A and four were in Child-Pugh B class, while the F4 group included 19 patients in class A and three in class B $(p=0.635)$.

Laboratory data and HCV-RNA. Table II summarizes the serum levels of AST and ALT, platelet count, WBC count, differential WBC count, and HCV-RNA level in each group. There were no significant differences in the serum AST and ALT levels among groups. The platelet count was significantly lower in the F4, and early HCC groups than in the F1 group (Figure 3), while there were no significant differences in the WBC count and differential WBC count among the groups. There were also no significant differences in serum HCVRNA levels and HCV serotypes among groups. 


\section{Flow cytometric detection of CD4-positive T cells}

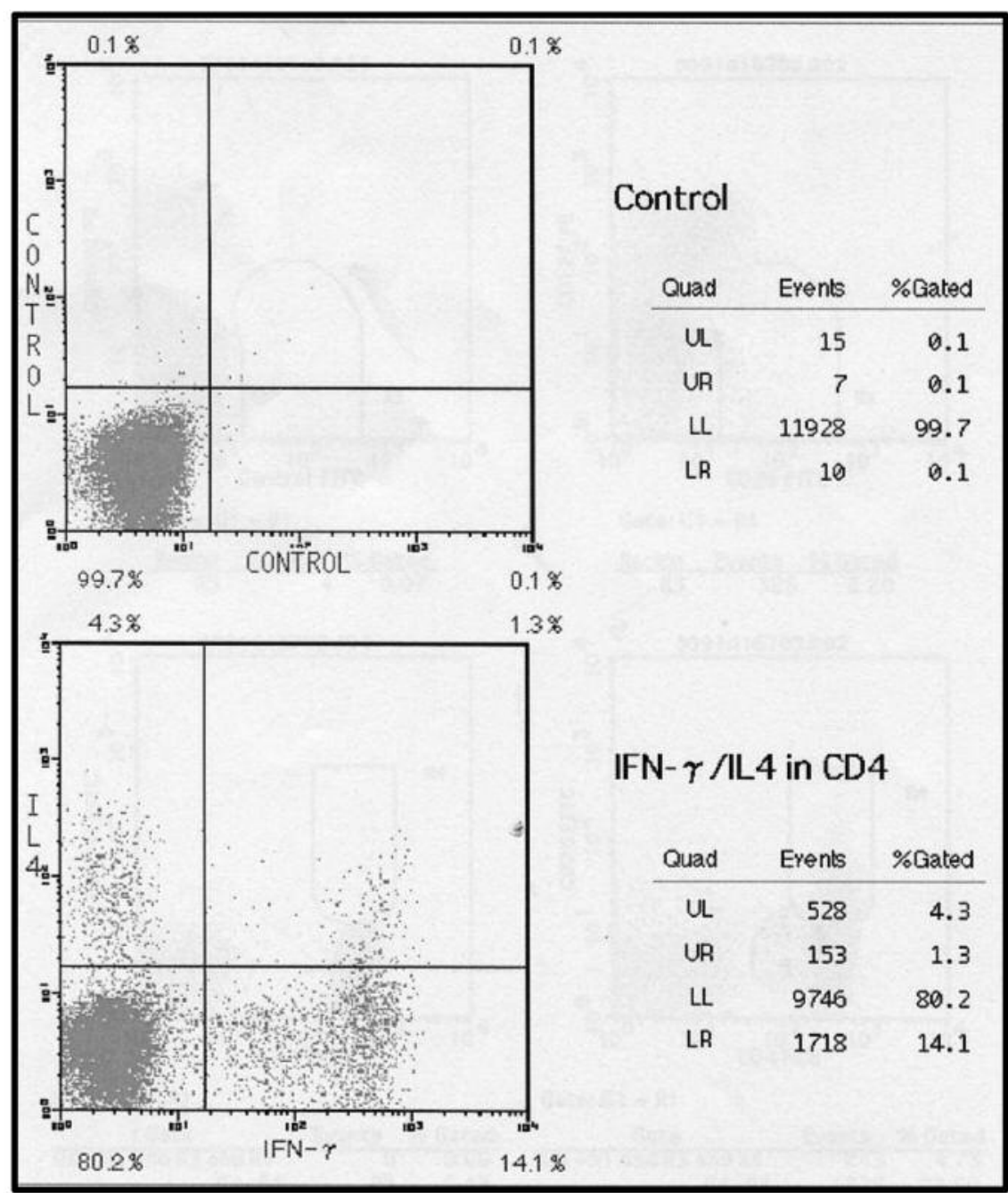

Upper left: IFN- $\gamma$ negative and IL-4 positive cells (Th2) Lower right: IFN- $\gamma$ positive and IL-4 negative cells (Th1)

Figure 1. Flow cytometric detection of interferon (IFN)- $\gamma$ and interleukin (IL)-4 in CD4-positive T-cells. Upper left: IFN $\gamma^{-}$and IL4+ cells (Th2); lower right: IFN $\gamma^{+}$and IL4- cells (Th1); upper right: IFN $\gamma^{+}$and IL4+ cells (ThO).

Laboratory data and HCV-RNA before and after RFA therapy. Changes of various parameters in the early HCC group were investigated by comparing data obtained before RFA and after RFA. There were no significant differences in serum AST, ALT, total bilirubin, albumin, prothrombin time, or platelet count between before and after RFA. There were also no significant differences in serum HCV-RNA levels between before and after RFA (Table III). With regard to serum levels of various tumor makers, such as $\alpha$-fetoprotein (AFP), the Lens culinaris agglutinin-reactive fraction of AFP (AFP-L3), and des- $\gamma$-carboxyprothrombin (DCP), there were
Table I. Clinical characteristics of the study subjects. Patients are shown according to degree of fibrosis (F1-4) or hepatocellular carcinoma $(H C C)$.

\begin{tabular}{lcccccc}
\hline & F1 & F2 & F3 & F4 & HCC & $p$ \\
\hline No. of patients & 21 & 21 & 18 & 22 & 21 & \\
Mean age \pm SD, years & $62.7 \pm 4$ & $63.0 \pm 5$ & $62.7 \pm 4$ & $63.5 \pm 6$ & $67.7 \pm 6$ & 0.053 \\
Gender (M/F) & $13 / 8$ & $13 / 8$ & $9 / 9$ & $11 / 11$ & $15 / 6$ & 0.591 \\
Child-Pugh class (A/B) & & & & $19 / 3$ & $17 / 4$ & 0.635 \\
\hline
\end{tabular}

M: Male; F: female. 

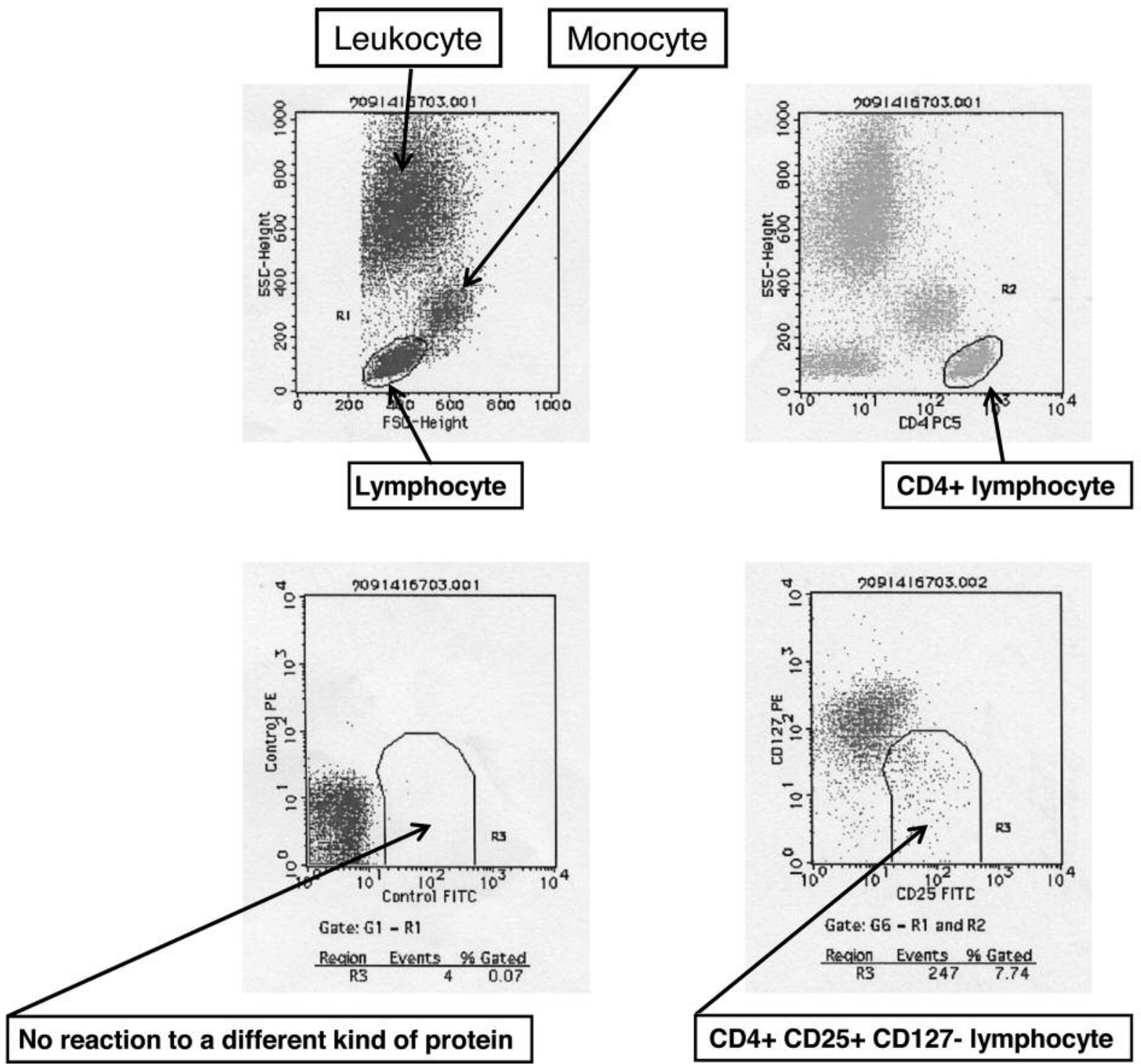

Figure 2. Flow cytometric detection of CD25-fluorescein isothiocyanate and CD127-phycoerythrin in CD4 ${ }^{+}$T-cells. Upper left: Leukocytes, monocytes, and lymphocytes; Upper right: $\mathrm{CD}^{+}$lymphocytes; lower left: no reaction to a different protein (control); lower right: $C D 4^{+}$and CD127-lymphocytes (Tregs).

also no significant differences between values before and after RFA (Figure 4).

Peripheral blood Th1 and Th2 cells. In the F4 group and the early HCC group before RFA, the percentage of Th1 cells was significantly higher than in the F1 group $(p \leq 0.05$ by Dunnet's test), although there was no significant difference between the F1 group and the early HCC group after RFA (Figure 5). Both before and after RFA, the percentage of Th2 cells was significantly higher in the early HCC group than in the F1 group ( $p \leq 0.05$ by Dunnet's test) (Figure 6 ). The proportion of Treg cells was significantly lower in the early
HCC group after RFA compared to that before RFA ( $p \leq 0.05$ by Wilcoxon's signed-rank sum test) (Figure 7), although there were no significant differences in Th1 and Th2 cells between before and after RFA (Figures 3 and 4). The changes of Th1, Th2, and Treg cells were not correlated with counts (data not shown).

\section{Discussion}

We previously reported that both Th1 and Th2 cells were increased in the peripheral blood of patients with HCVrelated chronic hepatitis and a high viral load compared to 
Table II. Comparison of clinical characteristics in patients with hepatitis C virus (HCV) infection according to degree of fibrosis (F1-4) or hepatocellular carcinoma (HCC).

\begin{tabular}{|c|c|c|c|c|c|c|c|}
\hline & \multirow[t]{2}{*}{$\mathrm{F} 1$} & \multirow[t]{2}{*}{$\mathrm{F} 2$} & \multirow[t]{2}{*}{ F3 } & \multirow[t]{2}{*}{$\mathrm{F} 4$} & \multicolumn{2}{|c|}{$\mathrm{HCC}$} & \multirow[t]{2}{*}{$p$-Value } \\
\hline & & & & & Pre RFA & Post RFA & \\
\hline AST IU/l) & $72.9 \pm 80$ & $72.7 \pm 69$ & $90.1 \pm 44$ & $67.9 \pm 31$ & $62.9 \pm 30$ & $65.8 \pm 37$ & 0.266 \\
\hline ALT (IU/l) & $100.9 \pm 104$ & $85.2 \pm 81$ & $119.1 \pm 63$ & $65.6 \pm 54$ & $61.1 \pm 38$ & $64.4 \pm 41$ & 0.052 \\
\hline White blood cell $\left(/ \mathrm{mm}^{3}\right)$ & $5165.2 \pm 1452$ & $5157.1 \pm 1235$ & $4933.3 \pm 1231$ & $4268.8 \pm 1316$ & $4717.7 \pm 1683$ & $4200.3 \pm 1845$ & 0.288 \\
\hline Lymphocyte $\left(/ \mathrm{mm}^{3}\right)$ & $1954.6 \pm 709$ & $1784.9 \pm 525$ & $2172.7 \pm 508$ & $1541.8 \pm 801$ & $1651.6 \pm 933$ & $1488.7 \pm 351$ & 0.054 \\
\hline Monocyte $\left(/ \mathrm{mm}^{3}\right)$ & $377.0 \pm 197$ & $420.9 \pm 163$ & $421.5 \pm 112$ & $381.4 \pm 177$ & $350.8 \pm 162$ & $325.2 \pm 113$ & 0.414 \\
\hline Platelet $\left(/ \mathrm{mm}^{3}\right)$ & $182190.5 \pm 40641$ & $158571.4 \pm 45498$ & $140666.7 \pm 42759$ & $106187.5 \pm 43393$ & $111647.1 \pm 46733$ & $112764.7 \pm 50539$ & $0.001 *$ \\
\hline HCV-RNA $(\log \mathrm{IU} / \mathrm{ml})$ & $5.28 \pm 0.8$ & $5.51 \pm 0.8$ & $5.33 \pm 0.6$ & $5.38 \pm 0.6$ & $4.10 \pm 2.3$ & $4.33 \pm 2.4$ & 0.610 \\
\hline $\begin{array}{l}\text { Serotype of } \mathrm{HCV} \\
\text { (group 1/group 2), n }\end{array}$ & $9 / 12$ & $14 / 7$ & $12 / 6$ & $18 / 4$ & $13 / 8$ & & 0.126 \\
\hline
\end{tabular}

RFA: Radiofrequency ablation; AST: aspartate aminotransferase, ALT: alanine aminotransferase. Data are the mean \pm SD unless otherwise stated.

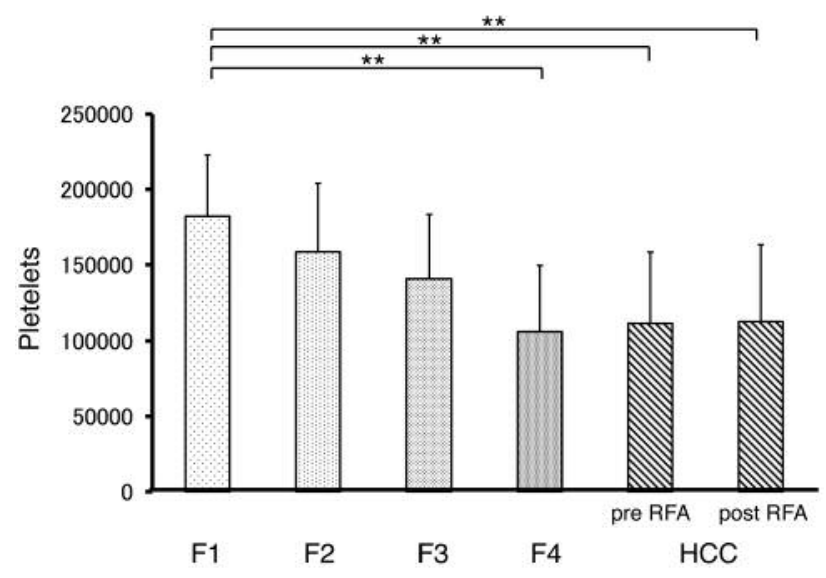

Figure 3. Comparison of the platelet count in different groups. The platelet count was significantly lower in the stage 4 of fibrosis (F4), and early hepatocellular carcinoma (HCC) groups than in the F1 group.

healthy volunteers, and we also reported that the percentages of both Th1 and Th2 cells in the peripheral blood were not associated with serum ALT in the patients with HCV-related chronic hepatitis (22). In the present study, serum levels of HCV-RNA and aminotransferases did not significantly differ among patients with HCV-related chronic hepatitis, LC, and early HCC. These results corresponded with our previous findings and suggest that inflammation of hepatocytes and the serum HCV load does not influence peripheral blood Th1/Th2 cell balance.

In the present study, the platelet count was significantly lower in the F4 group and early HCC group before and after RFA than in the F1 group, although there were no significant differences in serum AST, ALT, WBC count, and differential

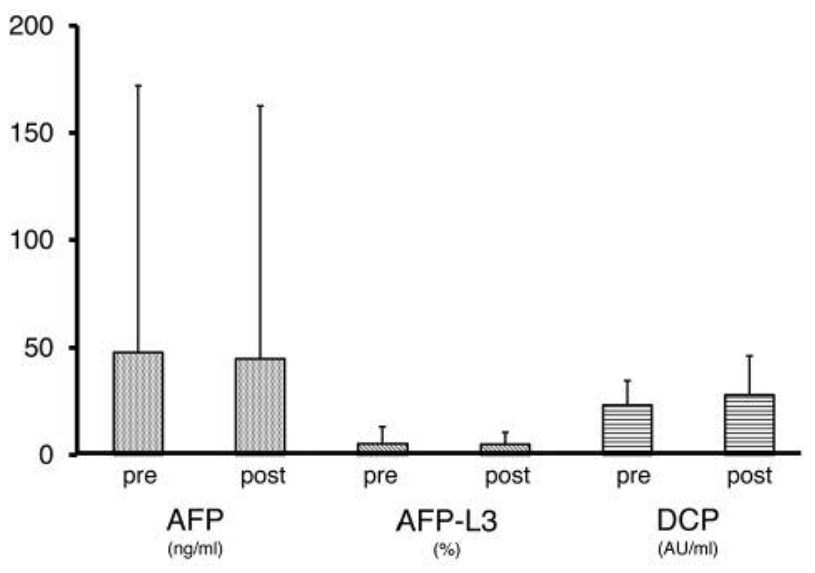

Figure 4. Comparison of tumor markers. With regard to serum levels of different tumor makers, such as $\alpha$-fetoprotein (AFP), the Lens culinaris agglutinin-reactive fraction of AFP (AFP-L3), and des- $\gamma$ carboxyprothrombin (DCP), there were also no significant differences in values between before and after radiofrequency ablation (RFA).

WBC count. Moreover, the platelet count was not significantly correlated with Th1, Th2, or Treg cells. It was reported that combining splenectomy with hepatectomy for patients with HCC with cirrhosis led to an increase of the platelet count, increase of Th1 cells, and a decrease of Th2 cells (27). Although splenectomy might cause an increase of Th1 cells and a decrease of Th2 cells, it is difficult to consider that a higher platelet count would lead to changes of these cells. In our patients with fibrocarcinogenesis, the platelet count seemed to reflect liver fibrosis, and a decrease in platelet count might not be related to carcinogenesis in this study population. 


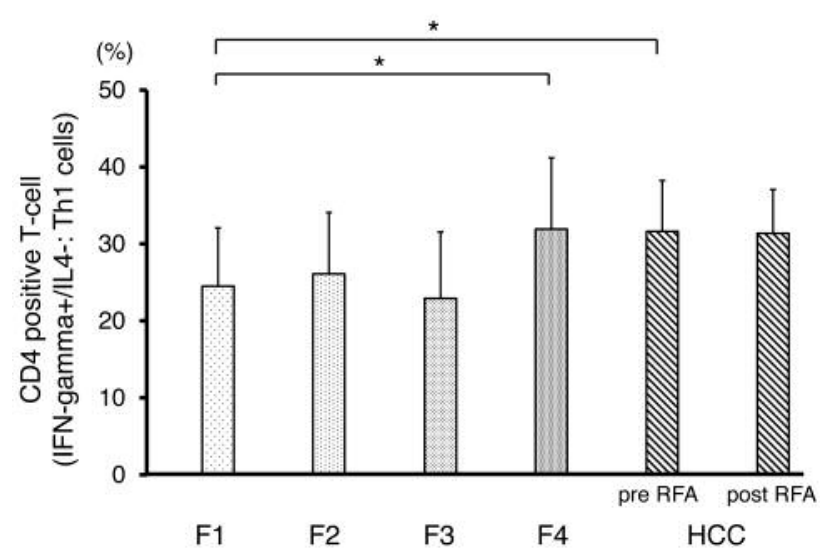

Figure 5. Comparison of the percentage of peripheral blood type 1 helper T (Th1)-cells. In the stage 4 of fibrosis (F4) group and the early hepatocellular carcinoma (HCC) group before radiofrequency ablation (RFA), the percentage of Th1 cells was significantly higher than in the stage 1 of fibrosis ( F1) group ( $p \leq 0.05$ by Dunnet's test), although there was no significant difference in values between the F1 group and the early HCC group after RFA.

Based on the cytokine production profile, helper T-cells can be divided into two distinct populations: Th1 and Th2 cells. These cells cross-regulate their own development. It was reported that an imbalance between Th1-like cytokines and Th2-like cytokines in the tumor microenvironment plays an important role in recurrence of HCC. In patients with metastatic HCC, liver tissue levels of Th1 cytokines are lower and levels of Th2 cytokines are much higher compared with the levels in patients without metastatic HCC (28). Of these cytokines, overexpression of IL2 and IL15 in peritumoral liver tissue, rather than in tumor tissue and serum, is significantly associated with a low incidence of intrahepatic recurrence and long overall survival (29). These reports indicate that $\mathrm{Th} 2$ dominance might be important for the occurrence of carcinogenesis. The response of T-cells to self- and non-self antigens is controlled by a network of Treg cells. $\mathrm{CD} 4{ }^{+}$cells that constitutively express CD25, the IL2 receptor $\alpha$-chain, are generally considered to be natural Treg cells, and account for $5-10 \%$ of peripheral $\mathrm{CD} 4^{+} \mathrm{T}$-cells in healthy animals and humans (30-32). There are two distinct subsets of Treg cells in peripheral lymphoid organs, natural Tregs that develop in the thymus after recognition of highaffinity self-antigens, and induced Tregs that develop from conventional T-cells after peripheral exposure to antigens and cytokines such as transforming growth factor $\beta$ or IL10 (33). These Treg cell subsets form the Treg network and may act synergistically to maintain immune homeostasis or may have different targets; these cells possibly also have a developmental role (34). It has been reported that circulating and tumor-infiltrating forkhead box P3+ Treg cells are

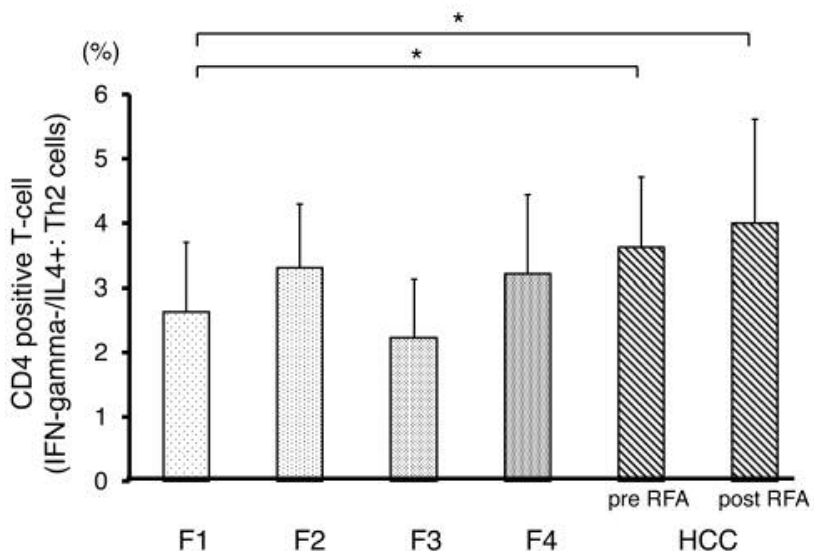

Figure 6. Comparison of the percentage of peripheral blood type 2 helper T (Th2)-cells. Both before and after radiofrequency ablation, the percentage of Th2 cells was significantly higher in the early hepatocellular carcinoma $(\mathrm{HCC})$ group than in the stage 1 of fibrosis (F1) group ( $p \leq 0.05$ by Dunnet's test).

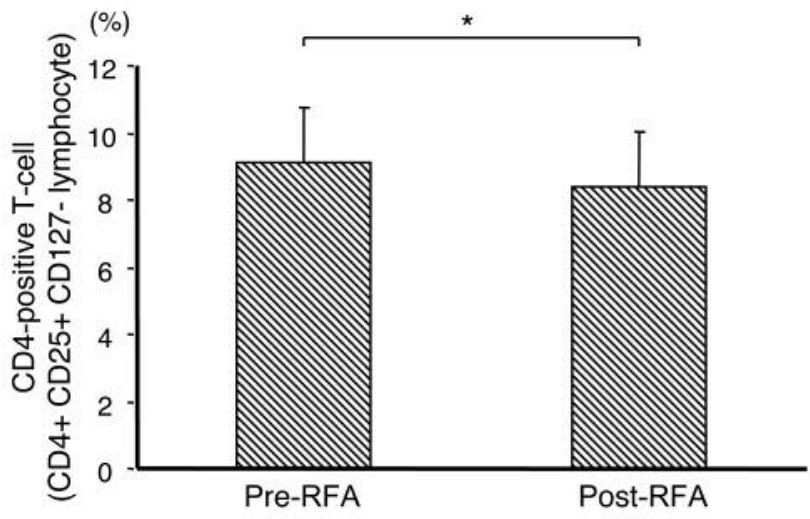

Figure 7. Comparison of the percentage of peripheral blood regulatory T-cells (Tregs). The proportion of Tregs was significantly lower in the early hepatocellular carcinoma (HCC) group after radiofrequency ablation (RFA) compared with that before RFA ( $p \leq 0.05$ by Wilcoxon's signed-rank sum test).

increased in patients with HCC (35). We have already reported that carcinogenesis in patients with HCV-related LC is associated with Th2 dominance (21), but we did not investigate then whether Th2 dominance induced carcinogenesis or carcinogenesis resulted in Th2 dominance. In the present study, the elimination of early HCC by RFA therapy led to normalization of Th1 cells and a decrease of Tregs. These results indicate that natural Tregs were not exposed to HCC antigens and induced Tregs decreased by 
elimination of early HCC after RFA therapy, with Th1 cells being normalized after the host immune system no longer needed to act against early HCC. After RFA therapy led to the elimination of early HCC, the percentage of Th2 cells continued to increase despite a decrease in Treg cells. These results indicate that Th2 might induce carcinogenesis in patients with $\mathrm{HCV}$-related LC rather than carcinogenesis leading to Th2 dominance. It was reported that the combination of depletion of Treg cells and concomitant stimulation of effector T-cells may represent an effective strategy for suppressing metastasis and recurrence of HCC $(36,37)$. Our findings in the present study support this report. In patients with $\mathrm{HCV}$-related $\mathrm{LC}$, it might be important to suppress Treg cells and Th2 cells for the prevention of carcinogenesis. Interestingly, it was reported that the annual incidence of HCC after SVR is higher in patients receiving IFN-free therapy than that in those receiving IFN-based therapy (38). In patients with $\mathrm{HCV}$ related diseases, examination of host immunological changes may be important for the prevention of carcinogenesis.

In conclusion, Th2 dominance was not altered by elimination of early HCC after RFA therapy. This suggests that Th2 dominance might induce carcinogenesis in patients with HCV-related LC rather than carcinogenesis resulting in Th2 dominance. However, further studies will be needed to examine the changes of host immunity in liver tissue because changes in serum parameters were observed in the present study.

\section{References}

1 Ferlay J, Shin HR, Bray F, Forman D, Mathers C and Parkin DM: Estimates of worldwide burden of cancer in 2008: GLOBOCAN 2008. Int J Cancer 127: 2893-2917, 2010.

2 Pawlotsky JM: New hepatitis C therapies: the toolbox, strategies, and challenges. Gastroenterology 146: 1176-1192, 2014.

3 Mc Combs J, Matsuda T, Tonnu-Mihara I, Saab S, Hines P, L'italien G, Juday T and Yuan Y: The risk of longterm morbidity and mortality in patients with chronic hepatitis $\mathrm{C}$ : results from an analysis of data from a Department of Veterans Affairs Clinical registry. JAMA Intern Med 174: 204-212, 2014.

4 Maylin S, Martinot-Peignoux M, Moucari R, Boyer N, Ripault MP, Cazals-Hatem D, Giuily N, Castelnau C, Cardoso AC, Asselah T, Féray C, Nicolas-Chanoine MH, Bedossa $\mathrm{P}$ and Marcellin P: Eradication of hepatitis $\mathrm{C}$ virus in patients successfully treated for chronic hepatitis C. Gastroneterology 135: 821-829, 2008.

5 Van der Meer AJ, Veldt BJ, Feld JJ, Wedemeyer H, Dufour JF, Lammert F, Duarte-Rojo A, Heathcote EJ, Manns MP, Kuske L, Zeuzem S, Hofmann WP, de Knegt RJ, Hansen BE and Janssen HL: Association between sustained virological response and allcause mortality among patients with chronic hepatitis $\mathrm{C}$ and advanced hepatic fibrosis. JAMA 308: 2584-2593, 2012.

6 Hsu YC, Ho HJ, Huang YT, Wang HH, Wu MS, Lin JT and Wu CY: Association between antiviral treatment and extrahepatic outcomes in patients with hepatitis $\mathrm{C}$ virus infection. Gut 64 : 495-503, 2015.
7 Hiramatsu N, Oze $\mathrm{T}$ and Takehara $\mathrm{T}$ : Suppression of hepatocellular carcinoma development in hepatitis $\mathrm{C}$ patients given interferon-based antiviral therapy. Hepatol Res 45: 152$161,2015$.

8 Tsai WL and Chung RT: Viral hepatocarcinogenesis. Oncogene 29: 2309-2324, 2010.

9 Matsuzaki K: Smad phosphoisoform signals in acute and chronic liver injury: similarities and differences between epithelial and mesenchymal cells. Cell Tissue Res 347: 225-243, 2012.

10 Dooley S, Hamzavi J, Ciuclan L, Dooley S, Hamzavi J and Ciuclan I: Hepatocyte-specific Smad7 expression attenuates TGF-beta-mediated fibrogenesis and protects against liver damage. Gastroenterology 135: 642-659, 2008.

11 Wada Y, Nakanishi O, Kutani R, Yamamoto O and Kojiro M: Clinicopathological study on hepatocellular carcinoma with lymphocytic infiltration. Hepatology 27: 407-414, 1998.

12 Mazzaferro V, Regalia E, Doci R, Andreola S, Pulvirenti A, Bozzetti F, Montaltof F, Ammatuna M, Morabito A and Gennari L: Liver transplantation for the treatment of small hepatocellular carcinoma in patients with cirrhosis. N Engl J Med 334: 693$700,1996$.

13 Canning C, O'Brien M, Hegarty $\mathrm{J}$ and O'Farrelly C: Liver immunity and tumor surveillance. Immunol Lett 107: 83-88, 2006.

14 Nakagawa H, Maeda S, Yoshida H, Tateishi R, Masuzaki R, Ohki T, Hayakawa Y, Kinoshita H, Yamakado M, Kato N, Shiina S and Omata M: Serum IL6 levels and the risk for hepatocarcinogenesis in chronic hepatitis C patients: An analysis based on gender differences. Int J Cancer 125: 22642269, 2009.

15 Budhu A and Wang XW: The role of cytokines in hepatocellular carcinoma. J leukoc Biol 80: 1197-1213, 2006.

16 Kobayashi M, Kobayashi H, Polland RB and Suzuki F: A pathogenic role of Th2 cells and their cytokine products on the pulmonary metastasis of murine B16 melanoma. J Immunol 160: 5869-5873, 1998.

17 Zitvogel L, Mayordomo JI, Tjandrawan T, DeLeo AB, Clarke MR, Lotze MT and Storkus WJ: Therapy of murine tumors with tumor peptide-pulsed dendritic cells: dependence on T-cells, B7 costimulation, and T helper cell 1-associated cytokines. J Exp Med 183: 87-97, 1996.

18 Tsung K, Meko JB, Peplinski GR, Tsung YL and Norton JA: IL12 induces T helper 1-directed antitumor response. J Immunol 158: 3359-3365, 1997.

19 Weiner GJ, Liu HM, Wooldridge JE, Dahle CE and Krieg AM: Immunostimulatory oligodeoxynucleotides containing the $\mathrm{CpG}$ motif are effective as immune adjuvants in tumor antigen immunization. Proc Natl Acad Sci USA 94: 10833-10837, 1997.

$20 \mathrm{Hu} \mathrm{HM}$, Urba WJ and Fox BA: Gene-modified tumor vaccine with therapeutic potential shifts tumor-specific $\mathrm{T}$ cell response from a type 2 to a type 1 cytokine profile. J Immunol 161: 303341, 1998.

21 Matsui T, Nagai H, Sumino Y and Miki K: Relationship of peripheral blood CD4-positive T-cells to carcinogenesis in patients with HCV-related chronic hepatitis and liver cirrhosis. Cancer Chemother Pharmacol 62: 271-276, 2008.

22 Takamura N, Ishii K, Shinohara M, Matsumaru K, Kawafune T and Sumino Y: Analysis of peripheral blood CD4 positive T-cells using intracellular staining method in patients with chronic hepatitis C. J Med Soc Toho 49: 45-52, 2002. 
23 Shinohara M, Ishii K and Takamura N: Long-term changes of peripheral blood CD4-positive $\mathrm{T}$ cell subsets (Th1, Th2) in chronic hepatitis $\mathrm{C}$ patients with a sustained response no response to IFN. Hepatol Res 27: 260-265, 2003.

24 Jung T, Schauer U, Heusser C, Neumann C and Rieger C: Detection of intracellular cytokines by flow cytometry. J Immunol Methods 159: 197-207. 1993.

25 Llovet JM, Di Bisceglie AM, Bruix J Kramer BS, Lencioni R, Zhu AX, Sherman M, Schwartz M, Lotze M, Talwalkar J and Gores GJ: Design and endpoints of clinical trials in hepatocellular carcinoma. J Natl Cancer Inst 100: 698-711, 2008.

26 Lencioni R and Llovet JM: Modified RECIST (mRECIST) assessment for hepatocellular carcinoma. Semin Liver Dis 30: 52-60, 2010.

27 Cao Z, Chen X and Wu Z: Effect of splenectomy in patients with cirrhosis undergoing hepatic resection for hepatocellular carcinoma. World J Gastroenterol 13(2): 280-284, 2007.

28 Coriat R, Gouya H, Mir O, Ropert S, Vignaux O, Chaussade S, Sogni P, Pol S, Blanchet B, Legmann P and Goldwasser F: Reversible decrease of portal venous flow in cirrhotic patients: a positive side effect of sorafenib. PloS One 6: e16978, 2011.

29 Fuchs BC, Hoshida Y, Fujii T, Wei L, Yamada S, Lauwers GY, McGinn CM, DePeralta DK, Chen X, Kuroda T, Lanuti M, Schmitt AD, Gupta S, Crenshaw A, Onofrio R, Taylor B, Winckler W, Bardeesy N, Caravan P, Golub TR and Tanabe KK: Epidermal growth factor receptor inhibition attenuates liver fibrosis and development of hepatocellular carcinoma. Hepatology 59: 1577-1590, 2014.

30 Shevach EM: Certified professionals: $\mathrm{CD} 4{ }^{+} \mathrm{CD} 25^{+}$suppressor T-cell. J Exp Med 193: F41-F46, 2001.

31 Stephens LA, Mottet C, Mason D and Powrie F: Human CD4+ $\mathrm{CD}^{+} 5^{+}$thymoctes and peripheral T-cells have immune suppressive activity in vitro. Eur J Immunol 31: 1247-1254, 2001.
32 Jonuleit H, Schmitt E, Stassen M, Tuettenberg A, Knop J and Enk AH: Identification and functional characterization of human $\mathrm{CD} 4{ }^{+} \mathrm{CD} 25^{+} \mathrm{T}$-cells with regulatory properties isolated from peripheral blood. J Exp Med 193: 1285-1294, 2001.

33 Zhou X, Bailey-Bucktrout SL, Jeker LT, Penaranda C, MartínezLlordella M, Ashby M, Nakayama M, Rosenthal W and Bluestone JA: Instability of the transcription factor Foxp3 leads to the generation of pathogenic memory T-cells in vivo. Nat Immunol 10: 1000-1007, 2009.

34 Horwitz DA, SG Zheng and Gray JD: Natural and TGF-betainduced Foxp3(+)CD4(+)CD25(+) regulatory T-cells are not mirror image of each other. Trends Immunol 29: 429-435, 2008.

35 Zhou J, Ding T, Pan W, Zhu LY, Li L and Zheng L: Increased intratumoral regulatory $\mathrm{T}$-cells are related to intratumoral macrophages and poor prognosis in hepatocellular carcinoma patients. Int J Cancer 1: 1640-1648, 2009.

36 Hato T, Goyal L, Greten TF, Duda DG and Zhu AX: Immune checkpoint blockade in hepatocellular carcinoma: current progress and future directions. Hepatology 60: 1776-1782, 2014.

37 Yang P, Markowitz GJ and Wang X-F: The hepatitis B virusassociated tumor microenvironment in hepatocellular carcinoma. Natl Sci Rev 1: 396-412.

38 Toyoda H, Kumada $\mathrm{T}$ and Tada $\mathrm{T}$ : Changes in patient backgrounds may increase the incidence of HCC after SVR in the era of IFN-free therapy for HCV. Hepatology 2016 May 2. doi: 10.1002/hep.28632. [Epub ahead of print] 